\title{
Mandala de Avaliação: oferta de um instrumento para realização de processos avaliativos no Apoio Institucional
}

Rebeca Silva de Barros ${ }^{(a)}$ Maria José Bistafa Pereira ${ }^{(b)}$ Claudia Benedita dos Santos ${ }^{(\mathrm{c})}$

Barros RS, Pereira MJB, Santos CB. Assessment Mandala: supply of an instrument to conduct evaluative processes in institutional support. Interface (Botucatu). 2018; 22(66):827-40.

Institutional support (IS), a methodological strategy for co-management, emerges as an innovation to promote institutional democracy in the Brazilian National Health System (SUS), being tested in the municipal, state and federal levels. A literature review was conducted and identified gaps in the scientific literature related to the education, follow-up, supervision and assessment of the work process of institutional supporters. This paper presents the Assessment Mandala as an instrument to conduct evaluative processes in IS with the aim of fostering dialogue among workers and managers. This instrument is grounded on permanent education in health, appreciative inquiry and participative management, and proposes directions to the evaluative process, guidance, and the permanent education of institutional supporters. The construction of this instrument allowed to define the attributes to assess the Support function: observation and listening; porosity; negotiation capacity; offers; activation of collective spaces, and team work.

Keywords: Participative management. Evaluate process. Institutional support.
O Apoio Institucional (Al), estratégia metodológica para a cogestão, surge como inovação para ampliação da democracia institucional no Sistema Único de Saúde (SUS), sendo experimentada nos níveis municipal, estadual e federal. A revisão de literatura identificou lacunas na publicação científica relacionada a: formação, acompanhamento, supervisão e avaliação do processo de trabalho de apoiadores institucionais. Este artigo apresenta a Mandala de Avaliação como instrumento para realização de processos avaliativos no $\mathrm{Al}$ com vistas à produção de diálogo entre os trabalhadores e a gestão. Este instrumento alicerçado na Educação Permanente em Saúde, na Avaliação Apreciativa e na gestão participativa, propõe pistas para o processo avaliativo, orientação e Educação Permanente de apoiadores institucionais. A construção deste instrumento permitiu definir os atributos para avaliar a função Apoio: observação e escuta; porosidade; capacidade de negociação; proposição de ofertas; ativação de espaços coletivos e trabalho em equipe.

Palavras-chave: Gestão participativa. Processo avaliativo. Apoio Institucional.

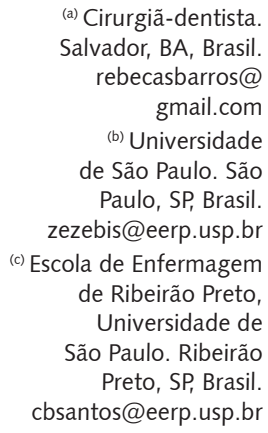

(a) Cirurgiã-dentista. Salvador, BA, Brasil. rebecasbarros@ gmail.com (b) Universidade de São Paulo. São Paulo, SP, Brasil. zezebis@eerp.usp.br (c) Escola de Enfermagem de Ribeirão Preto, Universidade de São Paulo. Ribeirão Preto, SP, Brasil. cbsantos@eerp.usp.br 


\section{Introdução}

O Ministério da Saúde do Brasil, em seu documento base da Política Nacional de Humanização (PNH) para gestores e trabalhadores do SUS, define Função Apoio como diretriz e dispositivo para ampliar a capacidade de reflexão, entendimento e análise de coletivos, que assim poderiam qualificar sua própria intervenção, sua capacidade de produzir mais e melhor saúde ${ }^{1}$.

No contexto da $\mathrm{PNH}$, a função do Apoio é considerada um recurso essencial para a instauração de processos de mudança, pois o objeto de trabalho do apoiador é o processo de trabalho de coletivos que se organizam para produção de saúde ${ }^{1}$.

Função Apoio foi definida por Oliveira² como o "papel institucional exercido por um agente que assume o posicionamento estético, ético e político de acordo com uma metodologia de apoio" (p. 46).

Ético porque o apoiador deve estar aberto para incluir as diferenças. Estético porque espera-se que este agente esteja disposto a criar estratégias a partir do cotidiano. Político porque configura-se como um mediador de negociações, compatibilizando interesses distintos mediante acordos.

Diferentemente das tradicionais funções de consultoria, assessoria ou supervisão, o "apoiador institucional" é um trabalhador das equipes de assistência ou gestão que atua na construção de Espaços Coletivos que permitam a análise, definição de tarefas e elaboração de projetos ${ }^{3}$.

Diante disso, considerando que as diretrizes do Apoio Institucional se constituem na democracia institucional e na autonomia dos sujeitos, foram propostos recursos metodológicos para o desenvolvimento desse trabalho. Dentre eles, destacam-se a: capacidade de construir rodas de diálogos; habilidade em incluir as relações de poder, de afeto e a circulação de conhecimentos em análise; capacidade de trabalhar com uma metodologia dialética em que o apoiador traga ofertas externas sem perder de vista a valorização dos saberes e das demandas do grupo apoiado; capacidade de pensar e fazer junto com as pessoas e não em lugar delas 4 .

Além destes, foram propostas ferramentas que, agregadas a aqueles ou a esses recursos, favoreceriam a capacidade de: negociação; produção de conexão; facilitação de processos que contribuam para colocar as potências em evidência; ação a partir do cotidiano, observando os movimentos da equipe e seu contexto, sempre aberto à escuta; assumindo uma postura pedagógica, tomando o mundo do trabalho como matéria-prima para o aprendizado 5 .

Duarte $^{6}$ aponta algumas características do processo de trabalho do Apoio Institucional, acrescentando: a capacidade de ouvir o outro; a flexibilidade e capacidade de improviso; o gosto por trabalhar com pessoas e pelo trabalho em equipe como componentes do trabalho do apoiador.

Falleiro e colaboradores ${ }^{7}$ ponderam que um apoiador, no início de sua caminhada, poderá tomar estes apontamentos como orientadores do seu fazer.

No entanto, questionamos os sentidos que os trabalhadores poderiam construir para essas recomendações s $^{3-5}$ porque é bastante provável que possam ser atribuídos a elas diversos sentidos, assim como poderia haver muita diversidade em sua operacionalização na realidade dos serviços possivelmente, vivenciadas de formas muito distintas e, quem sabe até, antagônicas na prática.

Em um contexto em que cada vez mais Organizações vêm procurando inovar no quesito gestão, duas grandes questões para aqueles que coordenam ou gerenciam equipes são: como perceber as habilidades dos trabalhadores de sua equipe? Como construir, com eles, a capacidade para o desenvolvimento da Função Apoio?

Considerando a importância de se aprofundar o conhecimento em torno dessa questão, este artigo pretende debater o tema da avaliação e apresentar a "Mandala de Avaliação" (MA) como oferta de instrumento para realização de processos avaliativos no Apoio Institucional para a produção de diálogo e educação permanente de apoiadores.

\section{Gestão do trabalho e avaliação no Apoio Institucional}

Para Campos ${ }^{8}$, um dos grandes desafios no âmbito da gestão no SUS é garantir tanto a produção qualificada de saúde quanto a realização de seus trabalhadores, estimulando-lhes a ampliação de sua capacidade de reflexão e de cogestão. 
Tradicionalmente, a teoria da administração científica tem grande influência na organização do trabalho e o gerenciamento no setor saúde ${ }^{4,9}$.

Estes modelos fundamentam-se em pressupostos que buscam o aumento da produtividade a partir da fragmentação do trabalho, com separação entre as etapas de concepção e de execução das tarefas, atrelado ao controle gerencial do processo produtivo e à hierarquia rígida, resultando, entre outras coisas, em desmotivação e alienação dos trabalhadores ${ }^{9}$.

Na perspectiva taylorista, o "chefe" assume uma postura de supervisão controlando o trabalho e o trabalhador de acordo com instruções e normas previamente estabelecidas. A tendência observada nas instituições que adotam esse tipo de organização no trabalho se traduz no pouco ou nenhum espaço para o exercício da autonomia e da liberdade; em alienação do trabalhador; na execução do trabalho de forma mecânica somente cumprida à custa da vigilância controladora do supervisor ${ }^{4,10}$.

De certa maneira, nas teorias clássicas da administração, a avaliação está relacionada a apreciar, estimar, criticar e controlar verificando se o desempenho do trabalhador atende às normas e padrões, previamente estabelecidos pela Organização.

Campos $^{10}$, no texto em que aborda o tema da subjetividade e da administração de pessoal, questiona se as instituições teriam sistemas participativos estruturados para captar tanto os problemas no desempenho das equipes quanto os problemas na relação entre Organização-trabalhador no sentido de ampliar a capacidade de autoanálise e autogestão dos grupos ou, se apenas teriam um sistema que serviria como aguilhão para empurrar profissionais em um sentido que interessaria somente às direções.

Neste tipo de relação trabalhador $x$ coordenador, tradicionalmente, espera-se do "chefe" que comande, defina, imponha, fiscalize e inspecione o trabalho estabelecendo uma relação assimétrica, hierárquica e pouco colaborativa 8,11 . Nestes contextos, a reprodução de práticas de gestão do trabalho que reforcem uma cultura de transferência de responsabilidade dos trabalhadores para os coordenadores é um risco iminente.

De fato, quando se está na função de coordenação se observa que pode existir uma certa tendência dos trabalhadores em apresentar demandas e desejar receber soluções prontas, imediatas. É como se o coordenador pudesse "tirar da cartola" a "receita mágica" para acabar com as tensões muitas vezes geradas na relação entre os próprios integrantes de uma equipe por conta de um conjunto complexo de dificuldades inerentes ao processo de comunicação, por conseguinte na integração dos membros da equipe.

Contudo, no sentido de se tornar um facilitador de processos, se faz necessário romper com essa tendência do coordenador se tornar o personagem "mágico" que acolhe e soluciona os problemas apontando as saídas ${ }^{12}$.

De acordo com Binsfeld et al., o Método Paidéia pressupõe o fortalecimento dos sujeitos e a democratização da Organização como os dois principais caminhos para a reformulação e superação da Racionalidade Gerencial Hegemônica ${ }^{13}$.

O Apoio Institucional como recurso metodológico procura fugir da tendência comum de várias escolas tradicionais de gerência que intervém sobre os trabalhadores, mas não atuam de maneira interativa com eles, supondo uma relação quase asséptica entre coordenador e trabalhador ${ }^{14}$.

Nessa perspectiva, com a finalidade de potencializar a autonomia, a criatividade, a liberdade e a responsabilidade dos trabalhadores, é fundamental que o coordenador incorpore na sua prática novas formas e novos recursos para coordenar, planejar, supervisionar e também avaliar.

Isso aponta para a necessidade de que o próprio gerente assuma a Função Apoio perante sua equipe de trabalho reconhecendo os trabalhadores não como meros insumos ("recursos humanos"), mas como potentes sujeitos na transformação do mundo e na implementação de políticas públicas de saúde.

Diante disso, a Educação Permanente em Saúde (EPS) é colocada como estratégica nos processos avaliativos porque toma os problemas do dia a dia como matéria prima para a reflexão sobre o processo de trabalho contribuindo para que o apoiador transforme sua realidade, adquira novas habilidades e competências.

Para Falleiro e colaboradores ${ }^{7}$, a EPS fortalece os trabalhadores porque promove sua pró-atividade, estimula a sua criatividade e propicia um campo fértil de produção de conhecimento a partir do cotidiano. 
Mori ${ }^{15}$ relata que a rotina do apoiador faz com que o mesmo entre em contato com muitas experiências intensas e que se faz necessário ressignificar estes processos cotidianamente por meio de EPS e da Supervisão do Apoio.

\section{Gestão participativa implica um outro modo de avaliar}

O Apoio é pensado como uma função gerencial que busca reformular o modo tradicional de fazer coordenação, planejamento, supervisão e avaliação em saúde ${ }^{3}$. Mas perguntamo-nos: como reformular este modo de fazer quando se trata de avaliação?

Podemos considerar a avaliação como resultado de um campo de conhecimento e práticas em constante desenvolvimento. No ano de 1989, Guba e Lincoln didaticamente criaram uma metáfora para apresentar a "história da avaliação" dividida em quatro gerações que são complementares entre si e fruto de um processo histórico evolutivo ${ }^{16-18}$.

A primeira geração (1910-1930) caracterizou a avaliação como "medida", sinônimo de aplicação de testes para medição de coeficiente de inteligência ou de memória, com o objetivo de comparar, classificar, certificar ou selecionar os participantes ao final do processo avaliativo.

A segunda geração (1930-1945) tratou a avaliação como "descrição", na qual a finalidade era elaborar novos currículos escolares com ênfase na relação ensino-aprendizagem, e o avaliador assumia uma postura de descritor. Nesta modalidade, eram definidos os objetivos a serem alcançados; verificado o alcance ou não destes pelos alunos, e descrito até que ponto eram atingidos os objetivos previamente definidos para todos.

Na terceira geração, desenvolvida após 1945, a avaliação ficou caracterizada como "apreciação do mérito" ou "juízo de valor", na qual o avaliador passava a assumir uma função de "juiz". O julgamento passa a subsidiar a tomada de decisões, considerando: os contextos de ensino e de aprendizagem, a definição de critérios e o envolvimento de professores, pais, alunos e outros intervenientes. Nesta geração, é introduzida a distinção entre o conceito de avaliação somativa e o conceito de avaliação formativa ${ }^{18}$.

A avaliação somativa se destina à tomada de decisão a respeito da extinção, manutenção ou expansão de um determinado programa ou serviço ${ }^{19}$. Já a avaliação formativa tem como finalidade o aperfeiçoamento por meio da identificação de fragilidades, e contempla a participação dos sujeitos diretamente envolvidos na busca por solução/ superação dos problemas identificados.

$\mathrm{Na}$ quarta geração (1980), a avaliação é compreendida como "negociação", assumindo um caráter formativo, incluindo a interação e a partilha de poder entre avaliador e avaliado e o feedback entre os participantes como forma de contribuir para o desenvolvimento e aprendizado de todos.

Entre 1980 e 1990, muitos pesquisadores refletiram sobre este tipo de abordagem no processo avaliativo e na construção de indicadores de avaliação ${ }^{16}$. Apesar de consensuarem que a emissão de juízo de valor era um desdobramento inevitável da avaliação, questionavam a insuficiência de que o julgamento se desse apenas com base em critérios, parâmetros ou referenciais externos ${ }^{16}$.

$\mathrm{Na}$ quarta geração, isso se tornou um diferencial, pois abriu a possibilidade para o engajamento das pessoas como sujeitos do processo avaliativo. Os chamados grupos de interesse são compostos por pessoas que agregam características comuns, como estudantes, gestores, usuários; se afetam por determinado programa ou serviço; e tenham algum interesse no objeto da avaliação 16,19,20.

Esta nova geração no campo da avaliação é decorrente da identificação de três limitações identificadas por Guba e Lincoln: a valorização do aspecto gerencial; a dificuldade em acomodar ideias e interesses divergentes; e a supremacia da visão científico-cartesiana da avaliação e do papel do avaliador ${ }^{16,17}$.

A avaliação de quarta geração encontra conexão com o Método Paidéia porque ambos se baseiam no referencial participativo-construtivista. Isto é, incluem a participação de atores sociais nos processos avaliativos ou de planejamento; ofertam espaços grupais de discussão que permitem aos participantes discutir, analisar e refletir sobre diferentes aspectos de um programa ou serviço a partir de seus próprios pontos de vista ${ }^{16}$.

Inspiradas nestes referenciais elaboramos a Mandala de Avaliação (MA) com a pretensão de propor uma ferramenta de avaliação de apoiadores e equipes de Apoio Institucional que transborde: a) a 
(d) A Mandala de Avaliação é um instrumento de domínio público para utilização conforme Guia Prático elaborado para auxiliar coordenadores e trabalhadores em processos avaliativos solicita-se apenas que seja citada a fonte. Entretanto, para adaptação do instrumento é necessária a solicitação de autorização para a pesquisadora responsáve pelo desenvolvimento deste instrumento. mensuração dos conhecimentos/ habilidades/ competências; b) a descrição de atividades ou c) o julgamento do trabalhador. Propõe-se a auxiliar os processos de coprodução de autonomia e responsabilização dos apoiadores por suas ações individuais e coletivas quando inseridos em determinado projeto ou Organização.

\section{A oferta de um instrumento ${ }^{(d)}$}

A MA é uma ferramenta que se alicerça na Educação Permanente em Saúde, na Avaliação Apreciativa, na gestão participativa e na avaliação participativa, e não se configura como um protocolo ou norma rígida a ser seguida. O que se propõe, por meio deste instrumento, são pistas para apoiar processos avaliativos, de integração e produção de diálogo no cotidiano do trabalho.

O nome 'Mandala de Avaliação' foi escolhido intencionalmente porque mandalas são figuras concêntricas e ancestrais que simbolizam a totalidade e a integração.

O instrumento é composto por: um gráfico de radar; um formulário com seis atributos, escala de respostas com cinco condições discriminantes (Nunca, Quase nunca, Algumas vezes, Muitas Vezes, Sempre), padronização de escore baseada em quartis e tipologia quanto ao desenvolvimento da Função Apoio, e guia prático com orientações para sua utilização.

$\mathrm{O}$ instrumento apresentado neste artigo foi validado do ponto de vista semântico e de conteúdo por meio de pesquisa de mestrado aprovada pelo Comitê de Ética da UEFS, parecer n $955.145^{21}$.

Na validação de conteúdo, submetemos o instrumento à apreciação de um comitê de juízes composto por 5 especialistas, aos quais solicitamos que fizessem sugestões, correções, acrescentassem ou modificassem os itens apresentados no instrumento ${ }^{22,23}$. O propósito desta etapa foi avaliar a relevância dos itens ao constructo em questão no tocante à organização e avaliação do processo de trabalho do Apoio Institucional. Para escolha dos especialistas, seguimos as recomendações destacadas na literatura, a saber: possuir experiência; publicar e pesquisar sobre o tema; ser perito na estrutura conceitual envolvida, e ter conhecimento metodológico sobre a construção de questionários e escalas ${ }^{23}$.

A validação semântica foi dividida em duas partes, geral e específica, para as quais utilizamos os formulários disponibilizados pelo grupo DISABKIDS no Brasil24 com a finalidade de verificar o entendimento que cada apoiador teve de cada uma das respectivas questões propostas para avaliação. Nesta etapa, participaram 27 apoiadores institucionais com formação na área da saúde, estatutários ou celetistas, vinculados à Secretaria de Saúde (municipal ou estadual), Ministério da Saúde (MS) ou Ministério da Educação (MEC), trabalhando in loco na sede dos ministérios ou trabalhando de forma descentralizada em outros Estados, comprometidos e/ou com experiência na gestão participativa.

\section{Atributos}

Os atributos estabelecidos para avaliação de trabalhadores e equipes que estejam desenvolvendo a função Apoio são: Observação e Escuta; Porosidade; Capacidade de Negociação; Proposição de Ofertas; Ativação de Espaços

Coletivos e Trabalho em Equipe 3,5,6,25-28. $^{\text {. }}$

O Quadro 1 apresenta os seis atributos, com uma breve definição, a serem observados no processo de trabalho no Apoio Institucional. 
Quadro 1. Atributos e breve definição que devem ser observados no processo de trabalho de apoiadores e equipes de Apoio Institucional.

\begin{tabular}{|l|l|}
\hline Atributo & Breve Definição \\
\hline $\begin{array}{l}\text { Observação e } \\
\text { Escuta }\end{array}$ & $\begin{array}{l}\text { Capacidade de planejar e intervir no território a partir da observação do cotidiano, escuta dos coletivos/ } \\
\text { sujeitos apoiados e registro das situações/ atividades vivenciadas. }{ }^{3,4,25}\end{array}$ \\
\hline Porosidade & $\begin{array}{l}\text { Abertura para encontros singulares e trocas de experiências mediante flexibilização de posturas, projetos } \\
\text { e metodologias de trabalho., } 4,6,25\end{array}$ \\
\hline $\begin{array}{l}\text { Capacidade de } \\
\text { negociação }\end{array}$ & $\begin{array}{l}\text { Compatibilização de interesses por meio de acordos, compromissos e contratos, de forma a compor } \\
\text { espaços de diálogo que possibilitem que os coletivos/ sujeitos apoiados possam encontrar formas de } \\
\text { continuarem a conviver ou encontrar soluçães para desafios comuns. }{ }^{3,4,16,26}\end{array}$ \\
\hline $\begin{array}{l}\text { Proposição de } \\
\text { ofertas }\end{array}$ & $\begin{array}{l}\text { Identificação de nós críticos no desenvolvimento de uma discussão/ atividade e apresentação de } \\
\text { metodologias, instrumentos, conceitos, referências, informações e relatos de experiências (ofertas) } \\
\text { pertinentes aos marcos teóricos do SUS, de forma articulada com a observação e escuta dos coletivos/ } \\
\text { sujeitos apoiados. }{ }^{2,3,4,16}\end{array}$ \\
\hline $\begin{array}{l}\text { Ativação de } \\
\text { Espaços Coletivos }\end{array}$ & $\begin{array}{l}\text { Postura pedagógica que utiliza o mundo do trabalho como matéria-prima para o aprendizado por meio } \\
\text { da: a) facilitação de grupos/ processos que contribuam para colocar as potências dos coletivos/ sujeitos } \\
\text { em evidência; e b) construção de rodas que propiciem a interação intersujeitos, a análise de situações } \\
\text { e a tomada de decisão mediante definição de contratos que se desdobrem em compartilhamento de } \\
\text { responsabilidades e tarefas. } 3,4\end{array}$ \\
\hline $\begin{array}{l}\text { Trabalho em } \\
\text { equipe }\end{array}$ & $\begin{array}{l}\text { Postura colaborativa na qual busca participar da construção de um projeto comum para a atuação } \\
\text { da equipe; está disponível para participar de encontros regulares para a discussão da organização do } \\
\text { processo de trabalho da equipe; estabelece comunicação direta com os colegas, compreendendo o } \\
\text { conflito como uma dimensão inerente ao trabalho em equipe e como potência para gerar crescimento e } \\
\text { construir a inovação; reconhece a interdependência de ações entre os integrantes da equipe. }\end{array}$ \\
\hline
\end{tabular}

Nas figuras 1 e 2, apresentamos o layout e parte do formulário da MA (atributo: Ativação de Espaços Coletivos).

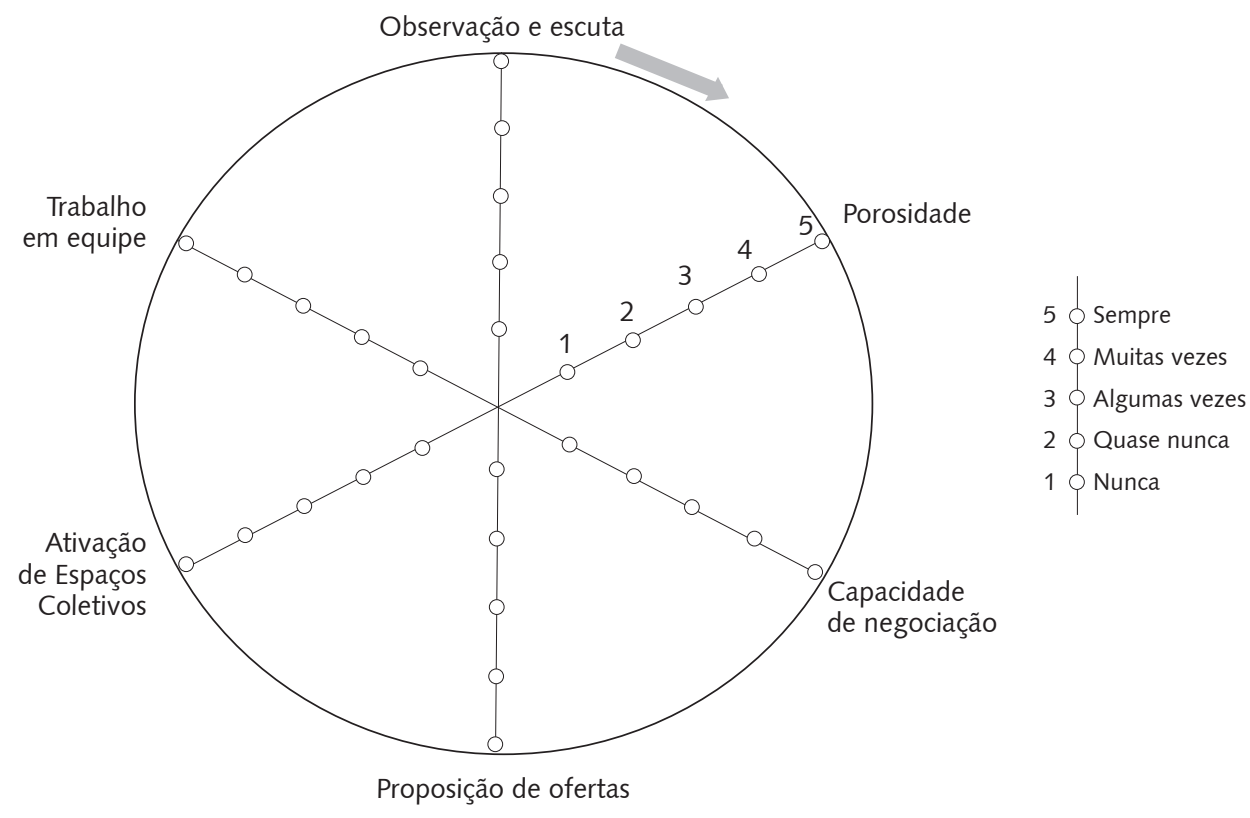

Figura 1. Layout da Mandala de Avaliação. Bahia, 2015. 


\begin{tabular}{|c|c|c|c|c|c|c|}
\hline \multirow{2}{*}{\multicolumn{2}{|c|}{ E - Ativação de Espaços Coletivos }} & \multicolumn{5}{|c|}{ Escala de respostas } \\
\hline & & \multirow{2}{*}{ Nunca } & \multirow{2}{*}{\begin{tabular}{|c|} 
Quase \\
Nunca
\end{tabular}} & \multirow{2}{*}{$\begin{array}{l}\text { Algumas } \\
\text { Vezes } \\
3\end{array}$} & \multirow{2}{*}{$\begin{array}{c}\text { Muitas } \\
\text { Vezes } \\
4\end{array}$} & \multirow{2}{*}{ Sempre } \\
\hline 1 & $\begin{array}{l}\text { Oferece suporte para a criação e o funcionamento de espaços de } \\
\text { gestão participativa como conselhos de cogestão; colegiados de gestão; } \\
\text { assembleias; reuniões; oficinas; grupos com funções especificas? }\end{array}$ & & & & & \\
\hline 2 & $\begin{array}{l}\text { Estimula e facilita a organização de espaços que permitam a participação } \\
\text { de outras pessoas que não apenas aqueles com função de direção, bem } \\
\text { como a de outros agentes externos ao } \\
\text { coletivo? }\end{array}$ & 1 & 2 & 3 & 4 & 5 \\
\hline 3 & $\begin{array}{l}\text { Facilita e organiza reuniões que favoreçam o diagnóstico, planejamento } \\
\text { e avaliação e monitoramento das ações? }\end{array}$ & 1 & 2 & 3 & 4 & 5 \\
\hline 4 & $\begin{array}{l}\text { Incentiva a construção de projetos e a tomada de decisão estabelecendo } \\
\text { contratos que definam os compromissos, as responsabilidades e as } \\
\text { tarefas compartilhadas por cada pessoa/ setor? }\end{array}$ & 1 & 2 & 3 & 4 & 5 \\
\hline 5 & $\begin{array}{l}\text { Estimula a organização de instâncias que possibilitem a integração e a } \\
\text { Educação Permanente a partir da troca de experiências e conhecimentos } \\
\text { entre as pessoas/ grupos apoiados, a análise de problemas, o } \\
\text { planejamento, o monitoramento e a avaliação das ações planejadas/ } \\
\text { executadas? }\end{array}$ & 1 & 2 & 3 & 4 & 5 \\
\hline 6 & $\begin{array}{l}\text { Constrói junto ao coletivo espaços para auto avaliação do grupo e } \\
\text { dos processos que dispara, possibilitando o redirecionamento das } \\
\text { ferramentas e estruturas organizacionais? }\end{array}$ & 1 & 2 & 3 & 4 & 5 \\
\hline
\end{tabular}

Figura 2. Formulário da Mandala de Avaliação (atributo "Ativação de Espaços Coletivos")

O processo avaliativo que utiliza a MA, se divide em duas etapas: etapa I - Autoavaliação, avaliação do(s) colega(s) de equipe e avaliação da equipe; e etapa II - Diálogo e construção de estratégias.

Para isso, cada participante recebe o instrumento impresso ou por meio de um arquivo em formato powerpoint. Metodologicamente, deve-se reservar um dia de encontro (carga horária de oito horas) para cada equipe de Apoio.

A avaliação se inicia com a apresentação geral do instrumento para que os participantes se apropriem dos itens e tenham oportunidade de esclarecer suas dúvidas.

Após a apresentação, cada participante, individualmente, preenche os formulários. Para possibilitar a marcação do escore na MA, o participante deverá obter o valor final da avaliação de cada atributo. Para isso, somam-se os valores assinalados em cada item e divide-se o resultado pelo número total de itens daquele atributo. O valor final obtido deverá ser marcado no campo correspondente a cada atributo avaliado. Por exemplo, o atributo "Ativação de Espaços Coletivos" é composto por seis itens. Devem ser somados os valores de cada item. O resultado desta soma será dividido por seis, obtendose, assim, o valor final do atributo. Os valores obtidos nestes cálculos poderão variar de 1 a 5 .

Ao final deste momento individual, todos os participantes deverão ter preenchido: sua mandala de AutoAvaliação, uma (1) mandala de avaliação para cada colega da equipe, e uma (1) mandala de avaliação da equipe.

Após obter o escore por atributo e preencher a MA, o participante deverá fazer o somatório de todos os valores assinalados.

Dessa forma, pode-se checar o grau de desenvolvimento da função Apoio de cada apoiador/ equipe, comparando a pontuação final obtida com a tipologia descrita no Quadro 2. 
Quadro 2. Escore final e tipologia quanto ao desenvolvimento da Função Apoio

\begin{tabular}{|c|c|}
\hline Escore final & Tipologia quanto ao desenvolvimento da função Apoio \\
\hline $6 \leq 12$ & Incipiente \\
\hline$>12 \leq 18$ & Parcial \\
\hline$>18 \leq 24$ & Avançado \\
\hline$>24 \leq 30$ & Pleno \\
\hline
\end{tabular}

\section{Revelando o processo de trabalho}

A MA é um tipo de gráfico de radar, o qual é uma representação ilustrativa ou um método gráfico que permite a agregação, a visualização e a apresentação, e comparação de diversos dados ao mesmo tempo. Para cada atributo avaliado, é criado um eixo, sendo que, quanto mais se aproximar do centro, menor o valor; e quanto mais se aproximar da extremidade do eixo, maior será o valor do atributo.

Para facilitar o processo avaliativo, o mediador deverá consolidar as pontuações em um único gráfico, com a finalidade de facilitar a visualização da avaliação geral por trabalhador e para a equipe.

Para isso, o mediador constrói uma "mandala síntese" para cada trabalhador com base nas marcações observadas nas mandalas preenchidas por cada participante.

Esta síntese é uma fotografia do momento atual de cada trabalhador ou equipe, e auxilia a mediação na medida em que revela as principais pistas que levarão o grupo ao diálogo sobre o processo de trabalho. A linha tracejada auxilia o mediador na análise desses pontos e pode ser delineada tomando como base a pontuação média em cada atributo.

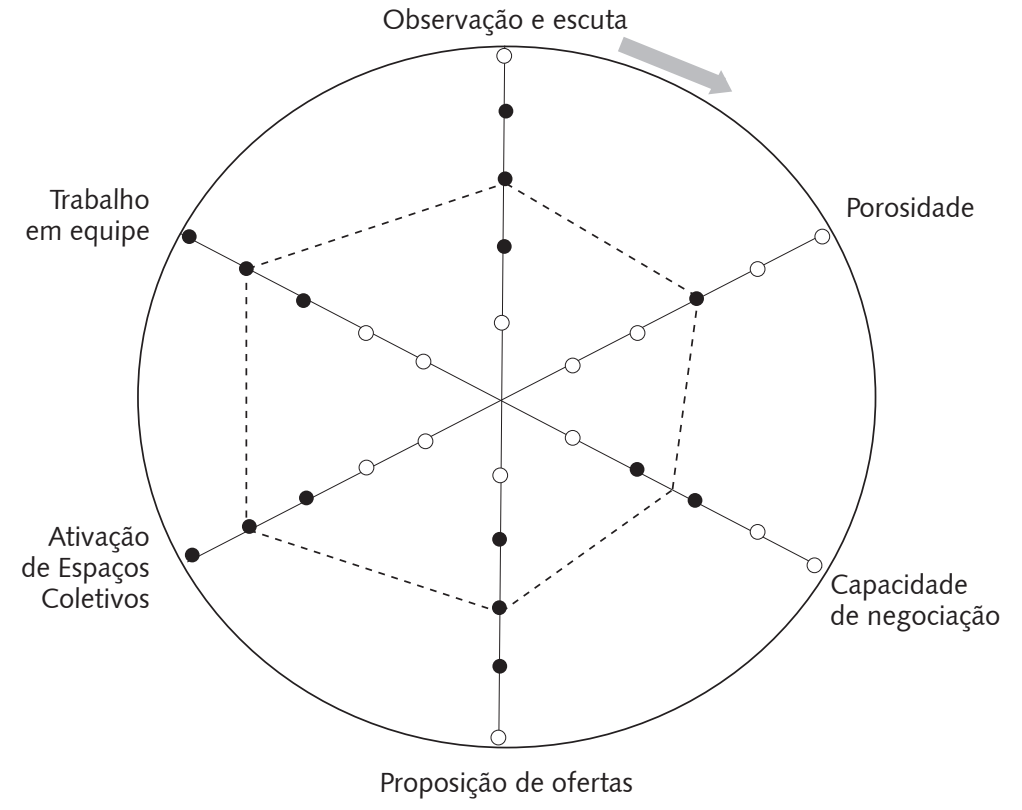

Figura 3. Simulação de preenchimento da Mandala de Avaliação - "mandala síntese" 


\section{Análise das mandalas síntese}

Recomenda-se a observação dos pontos convergentes e divergentes nestes gráficos consolidados, pois estes serão as pistas para o processo avaliativo, integração e produção de diálogo no cotidiano do trabalho. Para reconhecer os pontos convergentes, basta identificar os atributos que contêm apenas uma única marcação na escala de respostas. Na figura 3, o ponto de convergência está localizado no atributo "Porosidade". Para reconhecer os pontos de divergência, basta observar os atributos que apresentam duas ou mais marcações na escala de respostas.

Em geral, observa-se que os apoiadores com maior tempo de experiência na função Apoio apresentam uma tendência a ter uma mandala mais expandida e homogênea; e os apoiadores com menor tempo de experiência apresentam uma mandala mais distorcida e mais comprimida. Entretanto, isso não é uma regra porque a dinamicidade dos processos individuais se apresenta na conformação das mandalas.

\section{Mediação e interação}

A mandala síntese deverá ficar visível para todos os participantes. Este é o grande momento do processo avaliativo porque, de fato, é quando acontece o diálogo entre os participantes. É neste momento que os trabalhadores de uma mesma equipe se reúnem para dialogar sobre os escores obtidos e sobre seu contexto de trabalho.

Neste processo, sugere-se que o "avaliador" seja o próprio coordenador, colocando-o tanto como mediador, na medida em que facilita a abertura de linhas do processo de comunicação truncadas, quanto apoiador, na medida em que auxilia o grupo a experimentar uma autoanálise "com uma perspectiva crítica sem que ocorram tragédias e rupturas inoportunas. Analisar sem desqualificar o criticado; admitir erros e falhas sem destruir a auto-estima"2 (p. 191).

Para isso, o coordenador, na função de mediador do processo avaliativo, pode utilizar alguns recursos metodológicos que proporcionem a abertura de diálogo. Sugere-se cuidado na escolha do tipo de perguntas a serem feitas para o grupo neste momento. Ressalta-se que fazer perguntas sobre problemas convida as pessoas a estabelecerem discussões sobre "o que não dá certo" na sua realidade, podendo resultar no afastamento das pessoas, em respostas prontas e justificativas, restringindo, assim, a possibilidade de diálogo $29-32$.

Ao contrário disso, iniciar o processo fazendo perguntas sobre o que as pessoas apreciam no seu trabalho e sobre suas experiências de sucesso poderá facilitar o fluxo da conversa, auxiliar na construção de possibilidades e, consequentemente, na transformação da realidade ${ }^{29-32}$.

Neste sentido, "Avaliação Apreciativa" 32 torna-se um recurso metodológico, pois propõe a avaliação como "valorização". Em um processo avaliativo, a atitude de apreciação convida os participantes a iniciarem a interação por meio de perguntas sobre o que as pessoas apreciam no seu trabalho e sobre suas experiências de sucesso. Essa postura tende a facilitar o fluxo da conversa do grupo, auxiliar na construção de possibilidades e, consequentemente, na transformação de sua realidade. Iniciar o processo avaliativo com foco "no que dá certo" não significa que os problemas serão negligenciados, ignorados ou suprimidos. Estimular o grupo a falar sobre suas experiências positivas tende a fazer com que as pessoas se sintam mais confortáveis, e, quando os problemas forem abordados, estejam mais confiantes para construírem estratégias futuras para transformação de si mesmas e do grupo do qual participam ${ }^{29-32}$.

Brown ${ }^{33}$, em seu livro "A coragem de ser imperfeito", aborda o conceito de Vulnerabilidade dando destaque para os temas da vergonha e da importância do feedback como retorno de qualidade. Para a autora, os líderes devem conversar com sua equipe sobre seus pontos fortes e suas oportunidades de crescimento. Entretanto, em sua pesquisa, ela verificou que um retorno de qualidade não é algo comum porque as pessoas não se sentem à vontade com conversas difíceis ou, simplesmente, não sabem como dar e receber feedback de modo a fazerem o outro e os processos avançarem. 
Talvez esse seja um dos grandes nós críticos dos processos avaliativos: a vergonha de se expor, de deixar que o outro veja nossas fraquezas e pontos fracos. O medo da crítica destrutiva. Isso é algo que, em geral, tende a deixar as pessoas desconfortáveis.

A Comunicação Não Violenta (CNV) é um outro recurso metodológico que pode auxiliar a abertura de diálogo a partir de retornos de qualidade, pois contempla quatro passos (a) observação; b) identificação de sentimentos; c) expressão de necessidades; d) formulação de pedidos em linguagem positiva e de ações concretas) que auxiliam o processo de diálogo entre as pessoas, de modo a superarem, em sua interação, os padrões de defesa, recuo ou ataque diante de julgamentos e críticas ${ }^{34}$.

\section{Foco "no que dá certo"}

Iniciar o processo avaliativo com foco "no que dá certo", reforçamos, não significa que os problemas serão negligenciados, ignorados ou suprimidos. Estimular o grupo a falar sobre suas experiências positivas fará com que as pessoas se sintam mais confortáveis e, quando os problemas forem abordados, estejam mais confiantes para construírem estratégias futuras para transformação de si mesmas e do grupo do qual participam ${ }^{29-32}$.

Recomenda-se que o mediador mantenha sua atenção focada na forma com que as pessoas falarão sobre seu trabalho e na sua interação em equipe, pois isso reflete o que valorizam e o que as interessa mais naquele momento, como pensam e agem no cotidiano; as perguntas do mediador não procurarão respostas certas ou erradas, intencionalmente, o que será almejado é provocar a interação das pessoas durante o encontro.

\section{Vulnerabilidade}

Este tipo de processo avaliativo poderá gerar desconforto em alguns trabalhadores. Em geral, este sentimento emerge em decorrência da cultura organizacional tradicional que estimula a competição, a exposição dos erros e fracassos, a divisão das pessoas entre dois grupos: os bem-sucedidos e os malsucedidos. O resultado desta cultura é que as pessoas têm medo de serem ridicularizadas, humilhadas, censuradas ou culpadas ${ }^{33,34}$.

Diante disso, recomenda-se que o mediador esclareça os pressupostos do processo avaliativo e pactue com o grupo a confidencialidade e sigilo das questões que envolvam aspectos pessoais dos participantes, construindo com o grupo um espaço protegido, de confiança e vínculo que permitirá que todos sejam vistos tanto em sua força como em suas limitações.

\section{Finalizando a avaliação}

Ao final do encontro, é importante que os trabalhadores tenham dialogado sobre os pontos fortes e o que precisam transformar no seu processo de trabalho; e construído estratégias de forma colaborativa, visando a "solução" ou, pelo menos, a redução das dificuldades de natureza administrativa, contratual, ética, política e teórico-metodológica, apontadas na avaliação.

É recomendável que o mediador assuma compromissos com a equipe de forma a apoiá-la no desenvolvimento do seu processo de trabalho.

Sugere-se que o grupo conclua a atividade partilhando suas impressões sobre este processo.

\section{Considerações Finais}

Esta é uma ferramenta que tem potencial para proporcionar resultados objetivos e subjetivos. Objetivamente, ao final do processo avaliativo, todos os participantes poderão identificar o grau de desenvolvimento da função Apoio. Subjetivamente, os participantes terão a possibilidade de sentirse mais integrados, ouvidos, mobilizados e encorajados para concretizarem, de forma colaborativa, estratégias de intervenção e mudança para si, para a equipe e para a Organização. 
O referencial que sustentou tanto a elaboração, validação, bem como sustenta a utilização deste instrumento incluiu a escuta dos trabalhadores sobre as competências e habilidades necessárias para o desenvolvimento da função Apoio e as recomendações dos seguintes produções fundamentadas em referências teórico-metodológicos coerentes com a instauração de processos de mudança em grupos e organizações: Método Paideia; Avaliação de quarta geração; e dos seguintes recursos metodológicos: Comunicação Não Violenta; Vulnerabilidade; Avaliação Apreciativa.

Assim como na avalição participativa proposta por Guba e Lincoln, o que se espera neste processo avaliativo é a evidenciação das diferentes percepções e questões sobre o processo de trabalho dos apoiadores e da equipe de Apoio; a construção de um espaço de ampliação das habilidades individuais e coletivas; e a criação de espaços de negociação para construção do comum ${ }^{16}$.

Acreditamos que este processo avaliativo é possível de se estabelecer como um espaço pedagógico na lógica do Apoio para os trabalhadores e equipes. Segundo Reis e Hortale ${ }^{11}$, "suporte gera suporte" (p. 500). Para as autoras, as equipes de saúde que recebem suporte sentem-se cuidadas e compreendidas; dialogam sobre as limitações individuais e coletivas; constroem soluções para conflitos internos; e transmitem sua capacidade de suporte aos que necessitam de seus cuidados.

Neste sentido, poderíamos dizer que Apoio gera Apoio. Sendo que isto poderia ser a finalidade deste processo avaliativo, pois se pretende ir além da vigilância do coordenador sobre o desempenho do trabalhador porque pressupõe: a participação ativa; a abertura de espaços de diálogo; ampliação da capacidade de análise e de intervenção sobre o trabalho na Organização e no território apoiado. Ao invés da tradicional "supervisão", o coordenador passaria a desenvolver a "convisão" que significa gestão "co-laborativa" ou construção conjunta. ${ }^{11}$

A MA apresenta um enfoque para medir as habilidades relacionadas à condução e mediação de coletivos porque foi intencionalmente elaborada para provocar um processo avaliativo do apoiador e equipe de Apoio com base nos temas pertinentes ao processo de trabalho na Função Apoio, tais como o comprometimento com: a ampliação da capacidade de análise, a gestão participativa, a produção de diálogo, e modos de escuta e análise que facilitem posturas mais reflexivas.

\section{Colaboradores}

Rebeca Silva de Barros, Maria José Bistafa Pereira e Claudia Benedita dos Santos participaram, igualmente, da concepção, delineamento, análise e interpretação dos dados, redação do artigo, discussão dos resultados, revisão e aprovação da versão final do artigo.

\section{Referências}

1. Ministério da Saúde (BR). Secretaria de Atenção à Saúde. Núcleo Técnico da Política Nacional de Humanização. HumanizaSUS: documento base para gestores e trabalhadores do SUS. 4a ed. Brasília: Ministério da Saúde; 2008.

2. Oliveira GN. Devir apoiador: uma cartografia da Função Apoio [tese]. Campinas: Universidade Estadual de Campinas; 2011

3. Campos GWS. Um método para análise e co-gestão de coletivos. 3a ed. São Paulo: Hucitec; 2007. 
4. Campos GWS. Saúde paidéia. São Paulo: Hucitec; 2007.

5. Bertussi DC. O apoio matricial rizomático e a produção de coletivos na gestão municipal em saúde [tese]. Rio de Janeiro: Faculdade de Medicina, Universidade Federal do Rio de Janeiro; 2010.

6. Duarte CC. Como apoiar o Apoiador Institucional na perspectiva do próprio trabalhador-apoiador? [dissertação]. Feira de Santana: Universidade Federal de Feira de Santana; 2014.

7. Falleiro LM, Barros RS, Lima VCS, Duarte CC. Considerações preliminares sobre Apoio Institucional e Educação Permanente. In: Falleiro LM, organizadora. Experiências de apoio institucional no SUS: da teoria à prática. Porto Alegre: Rede UNIDA; 2014. p. 19-30.

8. Campos GWS. O anti-Taylor: sobre a invenção de um método para co-governar instituições de saúde produzindo liberdade e compromisso. Cad Saude Publica. 1998; 14(4):863-70.

9. Matos E, Pires D. Teorias administrativas e organização do trabalho: de Taylor aos dias atuais, influências no setor saúde e na enfermagem. Texto Contexto Enferm. 2006; 15(3):508-14.

10. Campos GWS. Subjetividade e administração de pessoal: considerações sobre modos de gerenciar o trabalho em equipes de saúde. In: Merhy EE, Onocko Campos RT, organizadores. Agir em saúde: um desafio para o público. São Paulo: Hucitec; 1998. p. 229-66.

11. Reis CCL, Hortale VA. Programa saúde da família: supervisão ou "convisão"? Estudo de caso em município de médio porte. Cad Saude Publica. 2004; 20(2):492-501.

12. Fortuna $C M$. O trabalho em equipe numa Unidade Básica de Saúde: produzindo e reproduzindo-se em subjetividades - em busca do desejo, do devir e de singularidades [dissertação]. Ribeirão Preto: Escola de Enfermagem de Ribeirão Preto, Universidade de São Paulo; 1999.

13. Binsfeld L, Hortale VA. Gerência de unidades básicas de saúde no Brasil e gestão estratégica: um contraponto. In: Garcia M, Hortale VA, organizadores. Políticas e gestão em saúde. Rio de Janeiro: Escola de Governo em Saúde. 2004. v. 2, p. 69-111.

14. Campos GWS, Figueiredo MD, Pereira Junior N, Castro CP. A aplicação da metodologia Paideia no apoio institucional, no apoio matricial e na clínica ampliada. Interface (Botucatu). 2014; 18 Supl 1:983-95.

15. Mori AY. Os sentidos de uma experiência ao habitar o território no Apoio Institucional descentralizado. In: Falleiro LM, organizador. Experiências de apoio institucional no SUS: da teoria à prática. Porto Alegre: Rede UNIDA; 2014. p. 161-84.

16. Furtado JP. Um método construtivista para a avaliação em saúde. Cienc Saude Colet. $2001 ; 6(1): 165-81$

17. Figueiró AC, Frias PG, Navarro LM. Avaliação em saúde: conceitos básicos para a prática nas Instituições. In: Samico I, Felisberto E, Figueiró AC, Frias PG, organizadores. Avaliação em saúde: bases conceituais e operacionais. Rio de Janeiro: MedBook; 2010. p. 2-14.

18. Vale SMM. A transição de um paradigma tradicional para uma avaliação autêntica das aprendizagens: uma cultura avaliativa em que os objetivos e os processos de ensino aprendizagem e avaliação são interdependentes [Internet]. 2011 [acesso 5 Nov 2014]. Disponível em: https://www.meloteca.com/pdf/susana-vale_avaliacao-reflexao-2.pdf.

19. Furtado JP. Avaliação de programas e serviços em saúde. In: Campos GWS, Bonfim JRA, Minayo MCS, Akerman M, Drumon Junior M, Carvalho YM, organizadores. Tratado de saúde coletiva. 2a ed. São Paulo: Hucitec; 2012. p. 221-46. 
20. Azevedo J, Valverde C. A perspectiva construtivista na avaliação de processos de intervenção e de formação [Internet]. 1999 [acesso 5 Nov 2014]. Disponível em: http:// repositorio.ucp.pt/bitstream/10400.14/3728/1/comnac_1999_FEG_1173_Valverde_ Camilo_04.pdf.

21. Barros RS. Mandala de avaliação: pistas para avaliação, integração e produção de diálogo no cotidiano do trabalho [dissertação]. Feira de Santana: Universidade Federal de Feira de Santana; 2015.

22. Hermida PMV, Araújo IEM. Elaboração e validação do instrumento de entrevista de enfermagem. Rev Bras Enferm. 2006; 59(3):314-20.

23. Alexandre NMC, Coluci MZO. Validade de conteúdo nos processos de construção e adaptação de instrumentos de medidas. Cienc Saude Colet. 2011; 16(7):3061-8.

24. The European DISABIKDS Group. The DISABKIDS questionaries. Quality os lyfe questionaires for children with chronic conditions. Handbook. Lengerich: Pabst Science Publishers; 2006.

25. Baduy RS. Gestão municipal e produção do cuidado: encontros e singularidades em permanente movimento [tese]. Rio de Janeiro: Faculdade de Medicina, Universidade Federal do Rio de Janeiro; 2010.

26. Campos GWS, Cunha GT, Figueredo MD, organizadores. Práxis e formação Paidéia: apoio e co-gestão em saúde. São Paulo: Hucitec; 2013. p. 50-70.

27. Peduzzi M. Equipe multiprofissional de saúde: conceito e tipologia. Rev Saude Publica. 2001; 35(1):103-19.

28. Fortuna CM, Mishima SM, Matumoto S, Bistafa Pereira MJ. O trabalho de equipe no Programa de Saúde da Família: reflexões a partir de conceitos do processo grupal e de grupos operativos. Rev Lat Am Enfermagem. 2005; 13(2):262-8.

29. Marujo HA, Afonso Neto LMV, Caetano A, Rivero C. Revolução positiva: psicologia positiva e práticas apreciativas em contextos organizacionais. Comport Organiz Gest [Internet]. 2007 [acesso 19 Ago 2015]; 13(1):115-36. Disponível em: http://repositorio. ispa.pt/bitstream/10400.12/147/1/COG \% 2013\% 281\% 29\% 20\% 282007\% 29\% 20115136.pdf.

30. Afonso Neto LMV. Tudo o que sempre quis saber sobre inquérito / indagação / investigação apreciativo/a em 10 perguntas (aparentemente) fáceis [Internet]. 2008 [acesso 19 Ago 2015]. Disponível em: http://inqueritoapreciativo.com/Tudo-o-quesempre-quis-saber-sobre-o-IA.pdf.

31. Rivero C. Inquérito apreciativo: sonhar as organizações, co-construir um futuro positivo e inovador [Internet]. 2008 [acesso 19 Ago 2015]. Disponível em: http:// inqueritoapreciativo.com/IA_Sonhar-as-Organizacoes.pdf.

32. Vilela e Souza L, Mcnamee S, Santos MA. Avaliação como construção social: investigação apreciativa. Psicol Soc. 2010; 22(3):598-607.

33. Brown B. A coragem de ser imperfeito. Rio de Janeiro: Sextante; 2013.

34. Rosenberg MB. Comunicação não-violenta: técnicas para aprimorar relacionamentos pessoais e profissionais. 4a ed. São Paulo: Ágora; 2006. 
Barros RS, Pereira MJB, Santos CB. Mandala de Evaluación: oferta de un instrumento para realización de procesos evaluadores en el Apoyo Institucional. Interface (Botucatu). 2018; 22(66):827-40.

El Apoyo Institucional (Al), estrategia metodológica para la cogestión, surge como innovación para la ampliación de la democracia institucional en el Sistema Brasileño de Salud (SUS) experimentada en el ámbito municipal, de los estados y federal. La revisión de la literatura identificó lagunas en la publicación científica relacionada a la formación, acompañamiento, supervisión y evaluación del proceso de trabajo de apoyadores institucionales. Este artículo presenta la Mandala de Evaluación como instrumento para la realización de procesos evaluadores en el Al con el objetivo de la producción de diálogo entre los trabajadores y la gestión. Este instrumento fundamentado en la Educación Permanente en Salud, en la Evaluación Apreciativa y en la gestión participativa, propone pistas para el proceso evaluador, orientación y Educación Permanente de apoyadores institucionales. La construcción de este instrumento permitió definir los atributos para evaluar la función Apoyo: observación y escucha; porosidad; capacidad de negociación; proposición de ofertas; activación de espacios colectivos y trabajo en equipo.

Palabras clave: Gestión participativa. Proceso evaluador. Apoyo Institucional. 